\title{
Interactions of Behavioral Changes in Smoking, High-risk Drinking, and Weight Gain in a Population of 7.2 Million in Korea
}

\author{
Yeon-Yong Kim, Hee-Jin Kang, Seongjun Ha, Jong Heon Park \\ Big Data Steering Department, National Health Insurance Service, Wonju, Korea
}

Objectives: To identify simultaneous behavioral changes in alcohol consumption, smoking, and weight using a fixed-effect model and to characterize their associations with disease status.

Methods: This study included 7000529 individuals who participated in the national biennial health-screening program every 2 years from 2009 to 2016 and were aged 40 or more. We reconstructed the data into an individual-level panel dataset with 4 waves. We used a fixed-effect model for smoking, heavy alcohol drinking, and overweight. The independent variables were sex, age, lifestyle factors, insurance contribution, employment status, and disease status.

Results: Becoming a high-risk drinker and losing weight were associated with initiation or resumption of smoking. Initiation or resumption of smoking and weight gain were associated with non-high-risk drinkers becoming high-risk drinkers. Smoking cessation and becoming a high-risk drinker were associated with normal-weight participants becoming overweight. Participants with newly acquired diabetes mellitus, ischemic heart disease, stroke, and cancer tended to stop smoking, discontinue high-risk drinking, and return to a normal weight.

Conclusions: These results obtained using a large-scale population-based database documented interactions among lifestyle factors over time.

Key words: Lifestyle, Smoking, Alcohol drinking, Overweight, Health risk behaviors

\section{INTRODUCTION}

Lifestyle factors such as alcohol consumption, smoking, and overweight are known to be important for health. Numerous studies of each component have been conducted, but few studies have sought to identify causal relationships between

Received: December 13, 2018 Accepted: June 7, 2019

Corresponding author: Yeon-Yong Kim, MD

Big Data Steering Department, National Health Insurance Service,

32 Geongang-ro, Wonju 26464, Korea

E-mail: yong115@hanmail.net

This is an Open Access article distributed under the terms of the Creative Commons Attribution Non-Commercial License (http://creativecommons.org/licenses/by$\mathrm{nc} / 4.0 / /$ which permits unrestricted non-commercial use, distribution, and reproduction in any medium, provided the original work is properly cited. lifestyle factors and health outcomes [1]. Some research findings, such as the so-called obesity paradox and the J-curve association between alcohol consumption and cardiovascular events, are likely to be attributed to the lack of an established causal relationship or the consequences of confounders [2-4]. If individuals attempt to lose weight, quit smoking, or abstain from alcohol after experiencing a severe disease or serious condition, the possibility of reverse causation between lifestyle behaviors and disease cannot be ruled out in cross-sectional studies [5-7]. In order to clarify the underlying causal relationships, a combination of various theories, instead of a single theory, or more advanced research methods are required to understand behavior change and maintenance [1].

Alcohol consumption, smoking, and weight often change at 
the same time and are related to each other. Drinking alcohol has been reported to have a positive association with smoking and obesity in various studies [8-12]. In contrast, some studies have reported an inverse relationship between obesity and alcohol consumption [13-15]. Many studies have reported a negative association between smoking and obesity [16-21]. If this relationship is not taken into consideration, it is possible to derive misleading results because of uncontrolled confounding factors. Furthermore, research results can be affected not only by observable confounding variables, but also by unobserved time-invariant confounding variables. To overcome the problem caused by the latter, fixed-effect models are known to be a good alternative for analyses of repeated measurement data [22]. Some studies using fixed-effect models have focused on simultaneous changes in smoking, alcohol consumption, and weight $[10,23]$. Of note, a previous study found that socioeconomic factors influenced changes in drinking patterns, underscoring the need for interventions [24]. Fixed-effect models can be used to analyze individual behavioral changes that are important for lifestyle modification [25].

The purpose of this study was to identify simultaneous behavioral changes in alcohol consumption, smoking, and weight with a fixed-effect model and to characterize their associations with disease status using the National Health Information Database (NHID) of the National Health Insurance Services (NHIS) in Korea. The database, which covers the entire population (about 50 million) of Korea, includes lifestyle-related variables for about 10 million people every year [26].

\section{METHODS}

\section{Data Sources}

The National Health Screening Program (NHSP) of Korea includes a questionnaire with items on smoking, alcohol consumption, and biometric information on height and weight. The NHSP includes screening examinations once every 2 years (every year for manual workers) for the entire population aged 40 or over and for employed and self-employed individuals under age 40 . The participation rate in the general health screening program was $77.7 \%$ in 2016 [27]. The NHID consists of 4 databases: the eligibility database, the national health screening database, the health care utilization database, and the long-term care insurance database. The health care utilization database collects claims data for inpatient and outpatient health care services. Because of the fee-for-service payment system, the NHID includes diagnosis, procedure, and prescription records in the health care utilization database. A retrospective cohort of the NHID (customized NHID) from 2009 to 2016 was used in this study (NHIS-2018-1-145).

\section{Study Participants and Variables}

The subjects of this study were those who participated in the NHSP every 2 years from 2009 to 2016 (2009-2010, 20112012, 2013-2014, and 2015-2016) and were aged 40 or more. Among the 17659972 participants in the NHSP in 2009-2010, a total of 9763476 received follow-up every 2 years. After excluding 2562947 people under age 40, 7200529 were included in this study. We reconstructed the data into an individuallevel panel dataset in 4 waves (2009-2010, 2011-2012, 20132014, and 2015-2016). Each wave panel dataset included sex, age, insurance type (the employed insured and dependents, and self-employed heads of household and family members), insurance-contribution quartile (a proxy indicator for household income, for which higher quartiles indicate higher income), moderate-risk/high-risk drinking status (based on the questionnaire about alcohol consumption frequency and standard drink amount, regardless of the type of alcohol; alcohol consumption of $40 \mathrm{~g} / \mathrm{d}$ or more for males and $20 \mathrm{~g} / \mathrm{d}$ or more for females [28]), overweight (based on the body mass index [BMI] calculated from measured height and weight, using a BMI of $25 \mathrm{~kg} / \mathrm{m}^{2}$ or more as a threshold), and current smoking status (based on the questionnaire). From the health care utilization database, participants' medical history of hypertension, diabetes mellitus, ischemic heart disease, stroke, and cancer was included in the analysis. Each disease was classified according to the primary diagnosis codes of the Korean Standard Classification of Diseases based on International Classification of Disease codes (hypertension, I10-115; diabetes mellitus, E10-E14; ischemic heart disease, 120-125; stroke, 160-164; cancer, C00-C97) and medication codes (hypertension and diabetes mellitus). Patients were only classified as having ischemic heart disease and stroke if they received inpatient care, and patients with cancer were defined as those whose medical copayment was reduced due to inclusion in the cancer registry.

To minimize selection bias due to regular health-screening participation, we created a stratified sampling weight variable according to sex, age group (40-49, 50-59, 60-69, 70+), and insurance type, which reflected the entire population of Korea aged 40 or over. 
Table 1. General characteristics of the study population

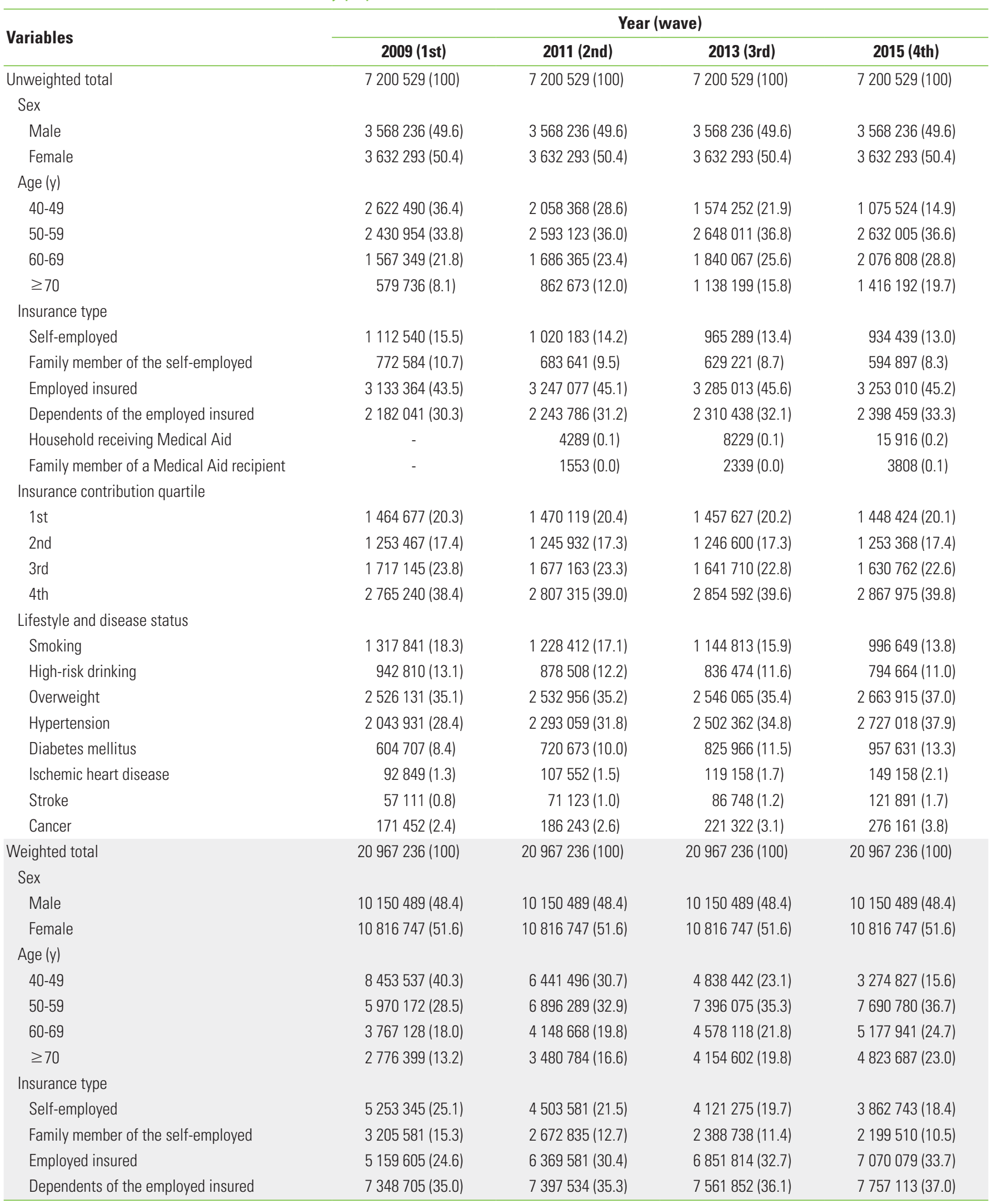


Table 1. Continued from the previous page

\begin{tabular}{lcccc}
\hline \multirow{2}{*}{ Variables } & \multicolumn{3}{c}{ Year (wave) } \\
\cline { 2 - 5 } & $\mathbf{2 0 0 9}(\mathbf{1 s t})$ & $\mathbf{2 0 1 1}$ (2nd) & $\mathbf{2 0 1 3}$ (3rd) & $\mathbf{2 0 1 5}$ (4th) \\
\hline Household receiving Medical Aid & - & $18412(0.1)$ & $35231(0.2)$ & $64640(0.3)$ \\
$\quad$ Family member of a Medical Aid recipient & - & $5292(0.0)$ & $8326(0.0)$ & $13151(0.1)$ \\
Insurance contribution quartile & & & & \\
1st & $3653305(17.4)$ & $4069782(19.4)$ & $4191134(20.0)$ & $4274468(20.4)$ \\
2nd & $3741638(17.8)$ & $3739202(17.8)$ & $3737951(17.8)$ & $3739105(17.8)$ \\
3rd & $5383147(25.7)$ & $5096074(24.3)$ & $4966227(23.7)$ & $4912938(23.4)$ \\
4th & $8189146(39.1)$ & $8062178(38.5)$ & $8071923(38.5)$ & $8040725(38.3)$ \\
Lifestyle and disease status & & & & \\
Smoking & $3833204(18.3)$ & $3561912(17.0)$ & $3320933(15.8)$ & $2887192(13.8)$ \\
High-risk drinking & $2770857(13.2)$ & $2584649(12.3)$ & $2466693(11.8)$ & $2346666(11.2)$ \\
Overweight & $7395184(35.3)$ & $7397770(35.3)$ & $7414270(35.4)$ & $7740064(36.9)$ \\
Hypertension & $6114715(29.2)$ & $6844535(32.6)$ & $7461801(35.6)$ & $8115492(38.7)$ \\
Diabetes mellitus & $1833500(8.7)$ & $2177323(10.4)$ & $2484661(11.9)$ & $2867509(13.7)$ \\
Ischemic heart disease & $289495(1.4)$ & $333390(1.6)$ & $371134(1.8)$ & $468605(2.2)$ \\
Stroke & $187306(0.9)$ & $228063(1.1)$ & $278038(1.3)$ & $393617(1.9)$ \\
Cancer & $500928(2.4)$ & $541007(2.6)$ & $641631(3.1)$ & $807092(3.8)$ \\
\hline
\end{tabular}

Values are presented as number (\%).

\section{Statistical Analysis}

The descriptive analysis of the subjects was presented by frequency according to their characteristics. We used a fixedeffect model for smoking status, heavy alcohol drinking, and overweight (dependent variable for each model). The independent variables were sex, age (as a continuous variable), lifestyle factors (smoking, heavy alcohol drinking, and overweight, except for the dependent variable of each model), insurance contribution quartile, employment status (using insurance type), and disease status (hypertension, diabetes mellitus, ischemic heart disease, stroke, and cancer). Stratification of the fixed-effect model analysis according to sex and age was performed. The sampling weights described in the 'study participants'section were applied to the analysis.

\section{Ethics Statement}

All components and procedures of this study were approved by the Institutional Review Board (IRB) of the National Health Insurance Service (IRB no. Sa-2018-HR-01-016).

\section{RESULTS}

\section{General Characteristics of the Study Population}

The general characteristics of the study population are presented in Table 1, including both unweighted and weighted results. The weighted first wave included more females (51.6\%) than males (48.4\%) out of a total of 20967236 participants. By type of insurance, dependents of the employed insured were the most frequent (35.0\%). Comparing the prevalence of various behaviors and conditions in the first and fourth waves, that of smoking decreased from $18.3 \%$ to $13.8 \%$, that of highrisk drinking decreased from $13.2 \%$ to $11.2 \%$, that of overweight increased from $35.3 \%$ to $36.9 \%$, that of hypertension increased from $29.2 \%$ to $38.7 \%$, that of diabetes mellitus increased from $8.7 \%$ to $13.7 \%$, that of ischemic heart disease increased from $1.4 \%$ to $2.2 \%$, that of stroke increased from $0.9 \%$ to $1.9 \%$, and that of cancer increased from $2.4 \%$ to $3.8 \%$.

\section{Fixed-effect Model}

The results of the fixed-effect model with the sampling weights applied are presented in Table 2. Non-smokers or exsmokers who received insurance eligibility of the employed insured type, changed from the fourth to the first quartile of insurance contribution, became high-risk drinkers, or lost weight often became smokers. However, participants who had newly acquired hypertension, diabetes mellitus, ischemic heart disease, stroke, or cancer often became non-smokers $\left(R^{2}=0.814\right)$. Non-high-risk drinkers who lost insurance eligibility of the employed insured type, changed from the first to the fourth quartile of insurance contribution, became smokers, or 
Table 2. Results of the fixed-effect model' for smoking, high-risk drinking, and overweight with sampling weights

\begin{tabular}{|c|c|c|c|c|c|c|c|c|c|}
\hline \multirow{2}{*}{ Variables } & \multicolumn{3}{|c|}{ Smoking } & \multicolumn{3}{|c|}{ High-risk drinking } & \multicolumn{3}{|c|}{ Overweight } \\
\hline & Coefficient & $t$-value & $p$-value & Coefficient & $t$-value & $p$-value & Coefficient & $t$-value & $p$-value \\
\hline Smoking & - & - & - & 0.064 & 240.82 & $<0.001$ & -0.049 & -171.94 & $<0.001$ \\
\hline High-risk drinking & 0.042 & 240.82 & $<0.001$ & - & - & - & 0.008 & 33.08 & $<0.001$ \\
\hline Overweight & -0.028 & -171.94 & $<0.001$ & 0.007 & 33.08 & $<0.001$ & - & - & - \\
\hline Age & -0.007 & -418.76 & $<0.001$ & -0.003 & -135.45 & $<0.001$ & 0.002 & 108.48 & $<0.001$ \\
\hline Sex & - & - & - & - & - & - & - & - & - \\
\hline \multicolumn{10}{|l|}{ Insurance type } \\
\hline Employed insured & 0.003 & 15.79 & $<0.001$ & -0.002 & -7.52 & $<0.001$ & 0.001 & 4.19 & $<0.001$ \\
\hline \multicolumn{10}{|c|}{$\begin{array}{l}\text { Insurance contribution quartile } \\
\text { (ref: 4th quartile) }\end{array}$} \\
\hline 1st quartile & 0.002 & 10.22 & $<0.001$ & -0.001 & -4.19 & $<0.001$ & -0.006 & -23.25 & $<0.001$ \\
\hline 2nd quartile & 0.002 & 11.77 & $<0.001$ & -0.001 & -5.45 & $<0.001$ & -0.004 & -16.92 & $<0.001$ \\
\hline 3rd quartile & 0.001 & 6.23 & $<0.001$ & -0.001 & -5.58 & $<0.001$ & -0.001 & -4.63 & $<0.001$ \\
\hline Hypertension & -0.014 & -76.46 & $<0.001$ & -0.001 & -6.27 & $<0.001$ & 0.014 & 55.16 & $<0.001$ \\
\hline Diabetes mellitus & -0.018 & -61.90 & $<0.001$ & -0.008 & -22.12 & $<0.001$ & -0.034 & -88.82 & $<0.001$ \\
\hline Ischemic heart disease & -0.014 & -43.19 & $<0.001$ & -0.006 & -15.69 & $<0.001$ & -0.006 & -13.71 & $<0.001$ \\
\hline Stroke & -0.011 & -28.39 & $<0.001$ & -0.009 & -19.40 & $<0.001$ & -0.007 & -14.41 & $<0.001$ \\
\hline Cancer & -0.030 & -92.46 & $<0.001$ & -0.024 & -59.53 & $<0.001$ & -0.017 & -39.14 & $<0.001$ \\
\hline $\mathrm{R}^{2}$ & & 0.814 & & & 0.635 & & & 0.804 & \\
\hline
\end{tabular}

${ }^{1}$ Each model was adjusted for all variables in the table.

gained weight often became high-risk drinkers. However, participants who had newly acquired hypertension, diabetes mellitus, ischemic heart disease, stroke, or cancer often became non-high-risk drinkers $\left(R^{2}=0.635\right)$. Non-overweight participants who received insurance eligibility of the employed insured type, changed from the first to the fourth quartile of insurance contribution, or became non-smokers or high-risk drinkers often became overweight. However, participants who had newly acquired diabetes mellitus, ischemic heart disease, stroke, or cancer often lost weight $\left(R^{2}=0.804\right)$.

The results were similar in the stratified analysis (Table 3 ), and the $R^{2}$ value was the largest in the 40-49 age group.

\section{DISCUSSION}

In this study, we analyzed the interactions of changes in smoking, high-risk drinking, and weight by applying a fixedeffect model, through a novel kind of panel-data analysis. High-risk drinking had a positive association with both smoking and overweight, but smoking had a negative association with overweight. That is, high-risk drinking can increase at the same time if someone starts smoking or resumes smoking after quitting, which also means that there is a high possibility of becoming obese if someone continues high-risk alcohol consumption or quits smoking. In previous studies, smoking, high-risk drinking, and overweight were noted as independent characteristics at specific time points; in contrast, this study has significant implications for changes in healthy lifestyle behavior.

The observed association between drinking alcohol and smoking supports the results of previous studies $[8,12]$. Regarding the relationship between drinking alcohol and obesity, controversy exists in the literature [9-11,13-15]; however, a positive relationship was found in this study. Regarding the relationship between smoking and obesity, our results support the findings of previous studies showing a negative correlation [16-21]. In the study of Arif and Rohrer [13], obesity was lower in light alcohol drinkers and higher in heavy alcohol drinkers than in non-drinkers. In our study, only high-risk drinking was analyzed, meaning that our results support those of Arif and Rohrer [13]'s study. Tolstrup et al. [14] reported an inverse relationship between the frequency of drinking alcohol and waist-circumference changes in a population-based study in Denmark. In the study of Tolstrup et al. [14], various factors, such as physical activity, caloric intake, smoking, and education level, were adjusted; however, the large difference 
Table 3. Stratified results of the fixed-effect model' for smoking, high-risk drinking, and overweight with sampling weights

\begin{tabular}{|c|c|c|c|c|c|c|c|c|c|}
\hline \multirow{3}{*}{ Stratification variable } & \multicolumn{9}{|c|}{ Explanatory variables } \\
\hline & \multicolumn{3}{|c|}{ Smoking } & \multicolumn{3}{|c|}{ High-risk drinking } & \multicolumn{3}{|c|}{ Overweight } \\
\hline & Coefficient & $t$-value & $p$-value & Coefficient & $t$-value & $p$-value & Coefficient & $t$-value & $p$-value \\
\hline \multicolumn{10}{|l|}{ Male } \\
\hline Smoking & - & - & - & 0.060 & 160.76 & $<0.001$ & -0.054 & -173.60 & $<0.001$ \\
\hline High-risk drinking & 0.040 & 160.76 & $<0.001$ & - & - & - & 0.008 & 31.55 & $<0.001$ \\
\hline Overweight & -0.052 & -173.60 & $<0.001$ & 0.012 & 31.55 & $<0.001$ & - & - & - \\
\hline $\mathrm{R}^{2}$ & \multicolumn{3}{|c|}{0.787} & \multicolumn{3}{|c|}{0.606} & \multicolumn{3}{|c|}{0.803} \\
\hline \multicolumn{10}{|l|}{ Female } \\
\hline Smoking & - & - & - & 0.073 & 173.17 & $<0.001$ & -0.021 & -25.66 & $<0.001$ \\
\hline High-risk drinking & 0.038 & 173.17 & $<0.001$ & - & - & - & 0.004 & 7.24 & $<0.001$ \\
\hline Overweight & -0.003 & -25.66 & $<0.001$ & 0.001 & 7.24 & $<0.001$ & - & - & - \\
\hline $\mathrm{R}^{2}$ & \multicolumn{3}{|c|}{0.725} & \multicolumn{3}{|c|}{0.549} & \multicolumn{3}{|c|}{0.804} \\
\hline \multicolumn{10}{|l|}{ Age (y) } \\
\hline \multicolumn{10}{|l|}{$40-49$} \\
\hline Smoking & - & - & - & 0.071 & 154.60 & $<0.001$ & -0.048 & -114.43 & $<0.001$ \\
\hline High-risk drinking & 0.043 & 154.60 & $<0.001$ & - & - & - & 0.009 & 27.01 & $<0.001$ \\
\hline Overweight & -0.034 & -114.43 & $<0.001$ & 0.010 & 27.01 & $<0.001$ & - & - & - \\
\hline $\mathrm{R}^{2}$ & \multicolumn{3}{|c|}{0.825} & \multicolumn{3}{|c|}{0.650} & \multicolumn{3}{|c|}{0.812} \\
\hline \multicolumn{10}{|l|}{$50-59$} \\
\hline Smoking & - & - & - & 0.064 & 137.98 & $<0.001$ & -0.053 & -109.38 & $<0.001$ \\
\hline High-risk drinking & 0.040 & 137.98 & $<0.001$ & - & - & - & 0.006 & 16.82 & $<0.001$ \\
\hline Overweight & -0.031 & -109.38 & $<0.001$ & 0.006 & 16.82 & $<0.001$ & - & - & - \\
\hline $\mathrm{R}^{2}$ & \multicolumn{3}{|c|}{0.806} & \multicolumn{3}{|c|}{0.618} & \multicolumn{3}{|c|}{0.808} \\
\hline \multicolumn{10}{|l|}{$60-69$} \\
\hline Smoking & - & - & - & 0.053 & 98.86 & $<0.001$ & -0.049 & -71.21 & $<0.001$ \\
\hline High-risk drinking & 0.039 & 98.86 & $<0.001$ & - & - & - & 0.006 & 9.70 & $<0.001$ \\
\hline Overweight & -0.022 & -71.21 & $<0.001$ & 0.003 & 9.70 & $<0.001$ & - & - & - \\
\hline $\mathrm{R}^{2}$ & \multicolumn{3}{|c|}{0.780} & \multicolumn{3}{|c|}{0.574} & \multicolumn{3}{|c|}{0.799} \\
\hline \multicolumn{10}{|l|}{$\geq 70$} \\
\hline Smoking & - & - & - & 0.044 & 57.39 & $<0.001$ & -0.037 & -27.35 & $<0.001$ \\
\hline High-risk drinking & 0.043 & 57.39 & $<0.001$ & - & - & - & 0.002 & 1.38 & $<0.001$ \\
\hline Overweight & -0.011 & -27.35 & $<0.001$ & 0.001 & 1.38 & $<0.001$ & - & - & - \\
\hline $\mathrm{R}^{2}$ & & 0.752 & & & 0.529 & & & 0.782 & \\
\hline
\end{tabular}

'Each model was adjusted for all variables in Table 2.

between alcohol drinkers and non-drinkers constituted a limitation in the baseline characteristics. Liu et al. [15] reported that, after adjusting for age, race, height, education, health status, smoking, diet, physical activity, and total non-alcoholic caloric intake, those who consumed 1.0-6.9 drinks/wk had a lower probability of weight loss or gain. However, for those who consumed $\geq 2.0$ drinks/d, the difference was not statistically significant. In addition, the focus of their research was purely on the effects of alcohol consumption, as calories were adjusted for in the model; this is a limitation because total ca- loric intake is the most important factor contributing to obesity. A previous study [29] reported that alcohol consumption does not reduce the intake of other calories; therefore, it is also plausible that obesity increases because of the calories contained in alcoholic beverages.

French et al. [10] reported that smoking cessation was negatively correlated with alcohol consumption and positively correlated with weight gain in a fixed-effect model. Although similar results were obtained in our study, the study of French et al. [10] has a limitation in that the sample size was about 
2000 and the age range was limited to those aged 50 and over. In our study, we derived results based on data from roughly 7.2 million people, and investigated the associations of lifestyle changes with major diseases.

Hypertension was positively correlated with overweight, as is already well known [30]. However, smoking and high-risk drinking were negatively associated with hypertension, diabetes mellitus, ischemic heart disease, stroke, and cancer. Overweight was negatively associated only with hypertension. As described in the Introduction section of the present study, we considered the possibility of confounders in the obesity paradox and the J-curve of alcohol and disease complications. The observation of a negative association supports the hypothesis that these relationships between lifestyle factors and disease status are confounded by lifestyle changes. Our study did not investigate long-term health effects, because it analyzed simultaneous changes through a fixed-effect model. However, it is expected that further epidemiological studies will be conducted based on the results of this study.

For the stratified results, the explanatory power of the model $\left(R^{2}\right)$ was higher in males and younger participants. In previous studies of attitudes towards smoking cessation, males and younger individuals were more likely to quit smoking [31-33]. The results of this study therefore support those of previous research, although further studies are needed to generalize these results.

There are some limitations to this study. First, given the limitations of the available variables, smoking and alcohol use data were obtained from a self-reported questionnaire, and the type of alcohol was not considered. Second, there may be have been inaccuracies in the disease codes, such as those for hypertension and diabetes mellitus, because of the characteristics of insurance claims data. Third, although this study applied sampling weights for the whole population, the possibility of selection bias still remains. Fourth, simultaneous changes were the primary focus of the analysis, so there may be limitations in the interpretation of causal relationships.

The results of this study documented interactions among lifestyle factors in a large-scale population-based dataset. These results will provide guidance on how lifestyle factors should be handled in future epidemiological studies, and suggest that policies targeting smoking, high-risk drinking, and obesity should be carried out complementarily, rather than independently.

\section{CONFLICT OF INTEREST}

The authors have no conflicts of interest associated with the material presented in this paper.

\section{ACKNOWLEDGEMENTS}

None.

\section{AUTHOR CONTRIBUTIONS}

Conceptualization: YYK, JHP. Data curation: YYK, SH, HJK. Formal analysis: YYK. Funding acquisition: None. Methodology: YYK. Project administration: None. Visualization: None. Writing - original draft: YYK. Writing - review \& editing: YYK, HJK, SH, JHP.

\section{ORCID}

Yeon-Yong Kim https://orcid.org/0000-0003-2179-8931

Hee-Jin Kang https://orcid.org/0000-0003-2788-6262

Seongjun Ha https://orcid.org/0000-0001-9664-0827

Jong Heon Park https://orcid.org/0000-0002-4749-5878

\section{REFERENCES}

1. Riekert KA, Ockene JK, Pbert L. The handbook of health behavior change. 3rd ed. New York: Springer; 2013, p. 1.

2. Lawlor DA, Hart CL, Hole DJ, Davey Smith G. Reverse causality and confounding and the associations of overweight and obesity with mortality. Obesity (Silver Spring) 2006;14(12):22942304.

3. Shaper AG, Wannamethee G, Walker M. Alcohol and mortality in British men: explaining the U-shaped curve. Lancet 1988; 2(8623):1267-1273.

4. Stokes A, Preston SH. Smoking and reverse causation create an obesity paradox in cardiovascular disease. Obesity (Silver Spring) 2015;23(12):2485-2490.

5. Flegal KM, Graubard BI, Williamson DF, Cooper RS. Reverse causation and illness-related weight loss in observational studies of body weight and mortality. Am J Epidemiol 2011;173(1):1-9.

6. Rehm J, Irving H, Ye Y, Kerr WC, Bond J, Greenfield TK. Are lifetime abstainers the best control group in alcohol epidemiology? On the stability and validity of reported lifetime abstention. Am J Epidemiol 2008;168(8):866-871. 
7. Ng Fat L, Cable N, Shelton N. Worsening of health and a cessation or reduction in alcohol consumption to special occasion drinking across three decades of the life course. Alcohol Clin Exp Res 2015;39(1):166-174.

8. Dawson DA. Drinking as a risk factor for sustained smoking. Drug Alcohol Depend 2000;59(3):235-249.

9. Suter PM. Is alcohol consumption a risk factor for weight gain and obesity? Crit Rev Clin Lab Sci 2005;42(3):197-227.

10. French MT, Norton EC, Fang H, Maclean JC. Alcohol consumption and body weight. Health Econ 2010;19(7):814-832.

11. Lourenço $S$, Oliveira A, Lopes $C$. The effect of current and lifetime alcohol consumption on overall and central obesity. Eur J Clin Nutr 2012;66(7):813-818.

12. Zimmerman RS, Warheit GJ, Ulbrich PM, Auth JB. The relationship between alcohol use and attempts and success at smoking cessation. Addict Behav 1990;15(3):197-207.

13. Arif AA, Rohrer JE. Patterns of alcohol drinking and its association with obesity: data from the Third National Health and Nutrition Examination Survey, 1988-1994. BMC Public Health 2005;5:126.

14. Tolstrup JS, Halkjaer J, Heitmann BL, Tjønneland AM, Overvad $\mathrm{K}$, Sørensen $\mathrm{Tl}$, et al. Alcohol drinking frequency in relation to subsequent changes in waist circumference. Am J Clin Nutr 2008;87(4):957-963.

15. Liu S, Serdula MK, Williamson DF, Mokdad AH, Byers T. A prospective study of alcohol intake and change in body weight among US adults. Am J Epidemiol 1994;140(10):912-920.

16. Filozof C, Fernández Pinilla MC, Fernández-Cruz A. Smoking cessation and weight gain. Obes Rev 2004;5(2):95-103.

17. Gruber J, Frakes M. Does falling smoking lead to rising obesity? J Health Econ 2006;25(2):183-197.

18. Mackay DF, Gray L, Pell JP. Impact of smoking and smoking cessation on overweight and obesity: Scotland-wide, cross-sectional study on 40,036 participants. BMC Public Health 2013; 13:348.

19. Williamson DF, Madans J, Anda RF, Kleinman JC, Giovino GA, Byers T. Smoking cessation and severity of weight gain in a national cohort. N Engl J Med 1991;324(11):739-745.

20. John U, Hanke M, Rumpf HJ, Thyrian JR. Smoking status, cigarettes per day, and their relationship to overweight and obesity among former and current smokers in a national adult general population sample. Int J Obes (Lond) 2005;29(10): 1289-1294.
21. Rásky E, Stronegger WJ, Freidl W. The relationship between body weight and patterns of smoking in women and men. Int J Epidemiol 1996;25(6):1208-1212.

22. Gunasekara Fl, Richardson K, Carter K, Blakely T. Fixed effects analysis of repeated measures data. Int J Epidemiol 2014;43(1): 264-269.

23. Picone G, Sloan F. Smoking cessation and lifestyle changes. Forum Health Econ Policy 2003. doi: https://doi.org/10.2202/ 1558-9544.1048.

24. van der Deen FS, Carter KN, McKenzie SK, Blakely T. Do changes in social and economic factors lead to changes in drinking behavior in young adults? Findings from three waves of a population based panel study. BMC Public Health 2014;14:928.

25. Allison PD. Fixed effects regression models. Los Angeles: SAGE; 2009, p. 14-18.

26. Cheol Seong S, Kim YY, Khang YH, Heon Park J, Kang HJ, Lee H, et al. Data resource profile: the national health information database of the National Health Insurance Service in South Korea. Int J Epidemiol 2017;46(3):799-800.

27. National Health Insurance Service. 2016 National health screening statistical yearbook. Wonju: National Health Insurance Service; 2017, p. 5 (Korean).

28. Ezzati M, Lopez AD, Rodgers AA, Murray CJ. Comparative quantification of health risks: global and regional burden of disease attributable to selected major risk factors; 2004 [cited 2019 Jul 7]. Available from: https://apps.who.int/iris/handle/10665/ 42770.

29. Tremblay A, Wouters E, Wenker M, St-Pierre S, Bouchard C, Després JP. Alcohol and a high-fat diet: a combination favoring overfeeding. Am J Clin Nutr 1995;62(3):639-644.

30. Modan M, Halkin H, Almog S, Lusky A, Eshkol A, Shefi M, et al. Hyperinsulinemia. A link between hypertension obesity and glucose intolerance. J Clin Invest 1985;75(3):809-817.

31. Smith PH, Bessette AJ, Weinberger AH, Sheffer CE, McKee SA. Sex/gender differences in smoking cessation: a review. Prev Med 2016;92:135-140.

32. Gilpin EA, Pierce JP. Demographic differences in patterns in the incidence of smoking cessation: United States 1950-1990. Ann Epidemiol 2002;12(3):141-150.

33. Messer K, Trinidad DR, Al-Delaimy WK, Pierce JP. Smoking cessation rates in the United States: a comparison of young adult and older smokers. Am J Public Health 2008;98(2):317-322. 